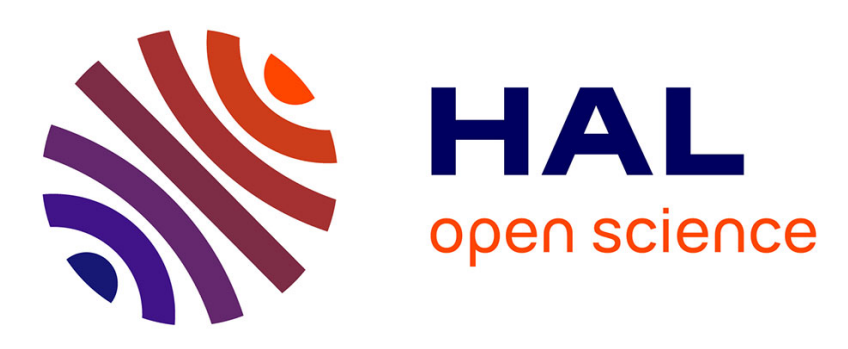

\title{
Improving the solar resource estimation in the United Arab Emirates using aerosol and irradiance measurements
}

\author{
Armel Oumbe, Helene Bru, Chao Li, Philippe Blanc, Lucien Wald, Hosni \\ Ghedira, Dominique Goffe
}

\section{To cite this version:}

Armel Oumbe, Helene Bru, Chao Li, Philippe Blanc, Lucien Wald, et al.. Improving the solar resource estimation in the United Arab Emirates using aerosol and irradiance measurements. ISES Solar World Conference 2015, Nov 2015, Daegu, South Korea. pp.200-208, 10.18086/swc.2015.07.08 . hal01511639

HAL Id: hal-01511639

https://hal-mines-paristech.archives-ouvertes.fr/hal-01511639

Submitted on 21 Apr 2017

HAL is a multi-disciplinary open access archive for the deposit and dissemination of scientific research documents, whether they are published or not. The documents may come from teaching and research institutions in France or abroad, or from public or private research centers.
L'archive ouverte pluridisciplinaire HAL, est destinée au dépôt et à la diffusion de documents scientifiques de niveau recherche, publiés ou non, émanant des établissements d'enseignement et de recherche français ou étrangers, des laboratoires publics ou privés. 


\title{
Improving the solar resource estimation in the United Arab Emirates using aerosol and irradiance measurements
}

\author{
Armel Oumbe ${ }^{1}$, Helene Bru ${ }^{1^{*}}$, Chao $\mathrm{Li}^{1}$, Philippe Blanc ${ }^{2}$, Lucien Wald ${ }^{2}$, Hosni Ghedira ${ }^{3}$ and Dominique \\ Goffe $^{4}$ \\ 1 Total New Energies, R\&D Solar, 92069 Paris La Défense, France \\ ${ }^{2}$ MINES ParisTech, PSL Research University, O.I.E. - Centre Observation, Impacts, Energy, CS 10207 - 06904 Sophia \\ Antipolis cedex, France \\ ${ }^{3}$ Masdar Institute, Research Center for Renewable Energy Mapping and Assessment, Abu Dhabi, PO Box 54224, United \\ Arab Emirates \\ ${ }^{4}$ Bertin Technologies, Energy Process Environment Department, 40220 Tarnos, France \\ * now at BHC Energy, 92100 Boulogne Billancourt, France
}

\begin{abstract}
A locally-adapted model to predict irradiance in the United Arab Emirates (UAE) has been developed. It is based on the McClear model and the HelioClim database, and it utilizes aerosol optical depth measurements from AERONET network, and high-precision measurements of irradiance collected at Madinat Zayed, UAE. The clear-sky part of the model consists of McClear model operated with ground-corrected Aerosol Optical Depth (AOD) as inputs. The all-sky part is made of HelioClim-3, recalculated with the AOD-corrected McClear as inputs, and then calibrated using irradiance measurements at one station. The locally-adapted model accurately estimates the global and direct irradiances. The estimated irradiances have been validated against measurements collected from 7 Rotating Shadowband Irradiometers distributed over the UAE. The obtained root mean square errors on the hourly means of irradiance are $4 \%$ for Global Horizontal Irradiance (GHI), $10 \%$ for Direct Normal Irradiance (DNI) in cloudless skies and $8 \%$ for GHI, $26 \%$ for DNI in cloudy skies.
\end{abstract}

Keywords: solar resource, irradiance, aerosol optical depth, UAE

\section{Introduction}

In many regions, the available solar resource data do not meet the requirements for solar plant simulation and feasibility studies. On the one hand, the satellite-based models that are used for long-term irradiance estimation are often not adapted to the potential sites of interest. Additionally, the measurements collected in ground-based stations are often not well processed and/or produced by not well maintained and calibrated stations. This is especially true for the regions where limited efforts have been made so far on the solar resource estimation, like in the Middle East. The research program Predisol aims to develop a locallyadapted tool to predict downwelling irradiances in desert environments in order to support present and future solar investments in the Middle East where the interest in solar power is rapidly increasing. The United Arab Emirates (UAE) have set a target to cover $7 \%$ of its electricity demand from renewable energy sources by 2020. As part of this effort, a 100 MW CSP plant, Shams-1, one of the largest plants of the World is operating in the middle of the UAE desert.

This paper presents the result of a joint effort between two research institutes and two private companies to improve the estimate of the solar resource in the Middle East region. State-of-the-art satellite-based models and irradiance measurement techniques have been used to improve the assessment of solar resource potential in the region. The high performance of McClear model (Lefèvre et al. 2014) in estimating the clear-sky 
irradiance in the UAE has already been demonstrated by Eissa et al. (2015). In this work, this performance has been enhanced thanks to a local adaptation with measurements of aerosol optical depth (AOD). The locally-adapted McClear is combined with the HelioClim-3 irradiance database (Blanc et al. 2011). The resulting model was then calibrated with high-precision measurements of irradiance collected from a ground station (AD1) located close to the Shams Power plant at Madinat Zayed, UAE.

\section{Method}

\subsection{Background}

\section{- $\quad$ McClear model}

McClear (Lefèvre et al. 2013) is a fully physical model that exploits the atmospheric properties provided by the EU-funded MACC (Monitoring Atmospheric Composition and Climate) project to estimate the surface downwelling solar irradiances in cloud-free conditions. McClear is based on the radiative transfer libRadtran (Mayer and Kylling, 2005) and uses a Look-Up-Table approach to enable routine calculations in real-time. The clearness indices - ratio between irradiance at the ground and irradiance at the top of the atmosphereobtained by running libRadtran are stored in the abaci. The values that contain the abaci are called node points. Interpolation functions are used to interpolate between these node points. An optimization was made for the selection of the node points and interpolation functions in order to (1) minimize the number of node points to keep abaci as small as possible, (2) interpolate/extrapolate functions as fast as possible, and (3) obtain low differences with libRadtran outcomes: bias less than $3 \mathrm{Wm}^{-2}$, and $95 \%$ of the differences less than $20 \mathrm{Wm}^{-2}$.

The comparison between McClear irradiances and measurements from the Baseline Solar Radiation Network (BSRN) on various climates has shown that McClear offers similar or better performances (Lefèvre et al. 2013). In addition, Eissa et al. (2015) performed validations of the McClear model in the United Arab Emirates, and compared McClear's performances against the performance of two other models in the literature. They concluded that McClear was better in capturing the temporal variability of the DNI and similar performances were obtained for the GHI retrieval in this desert climate. They also observed an underestimation in estimating the DNI, which was explained by the overestimation of the AOD in the MACC data and the not accounting for the circumsolar radiation in McClear model.

- Helioclim-3 database

The HelioClim-3 (Blanc et al. 2011) surface solar radiation database is based on the irradiances retrieved from Meteosat Second Generation satellite images. This satellite-based method used to estimate the irradiances is named Heliosat-2. The principle of Heliosat-2 (Rigollier et al. 2004) is that the attenuation of the downwelling shortwave irradiance by the atmosphere over a pixel is determined by the magnitude of change between the reflectance that should be observed under a very clear sky and the currently observed one. The HelioClim-3 database covers Europe, Africa, the Mediterranean Basin, the Atlantic Ocean and part of the Indian Ocean with a spatial resolution of approximately $5 \mathrm{~km}$ and a temporal resolution up to 15 minutes and contains irradiance estimates from February 2004 onwards. The HelioClim databases are commercialized by Transvalor and are available, with other solar related web-services, at www.soda-is.com.

Qu et al. (2014) demonstrated the advantage of replacing the clear-sky model in HelioClim-3 with McClear. They obtained an improvement of HelioClim-3 in most cases, and with no degradation in the others.

\subsection{Scheme}

The all-sky irradiance is computed as a product between clear-sky (or cloud-free sky) irradiance and a clearsky index (Oumbe et al., 2014). The following two ratios, Kc and Kcb, are called clear-sky indices (Beyer et al., 1996):

$$
\begin{aligned}
& \mathrm{Kc}=\mathrm{GHI} / \text { GHIclear-sky } \\
& \mathrm{Kcb}=\mathrm{DNI} / \text { DNIclear-sky }
\end{aligned}
$$

The estimation of irradiance under clear-sky condition is based on the McClear model. It has been observed 
that the error on MACC AOD estimations leads to important deviations on the clear-sky irradiances in the region: up to $20 \%$ on DNI if the deviation is expressed as a root mean square deviation (Oumbe et al. 2013). The MACC AODs have been therefore calibrated using AOD measured by AERONET (Aerosol Robotic Network) stations in the UAE before being used as input for irradiance calculation in the region.

The clear-sky index, $\mathrm{Kc}_{\mathrm{HC} 3}$, was extracted from HelioClim-3 database. The obtained all-sky irradiances are then locally adapted using the measurements collected at AD1. The probability density function of the difference $\mathrm{Kc}_{\mathrm{HC} 3}-\mathrm{Kc}_{\mathrm{AD} 1}$ is estimated by a model which is then applied to all locations and periods to correct the $\mathrm{Kc}_{\mathrm{HC} 3}$. Eventually, the $\mathrm{GHI}_{\text {estimated }}$ and $\mathrm{DNI}_{\text {estimated }}$ are derived (Figure 1).

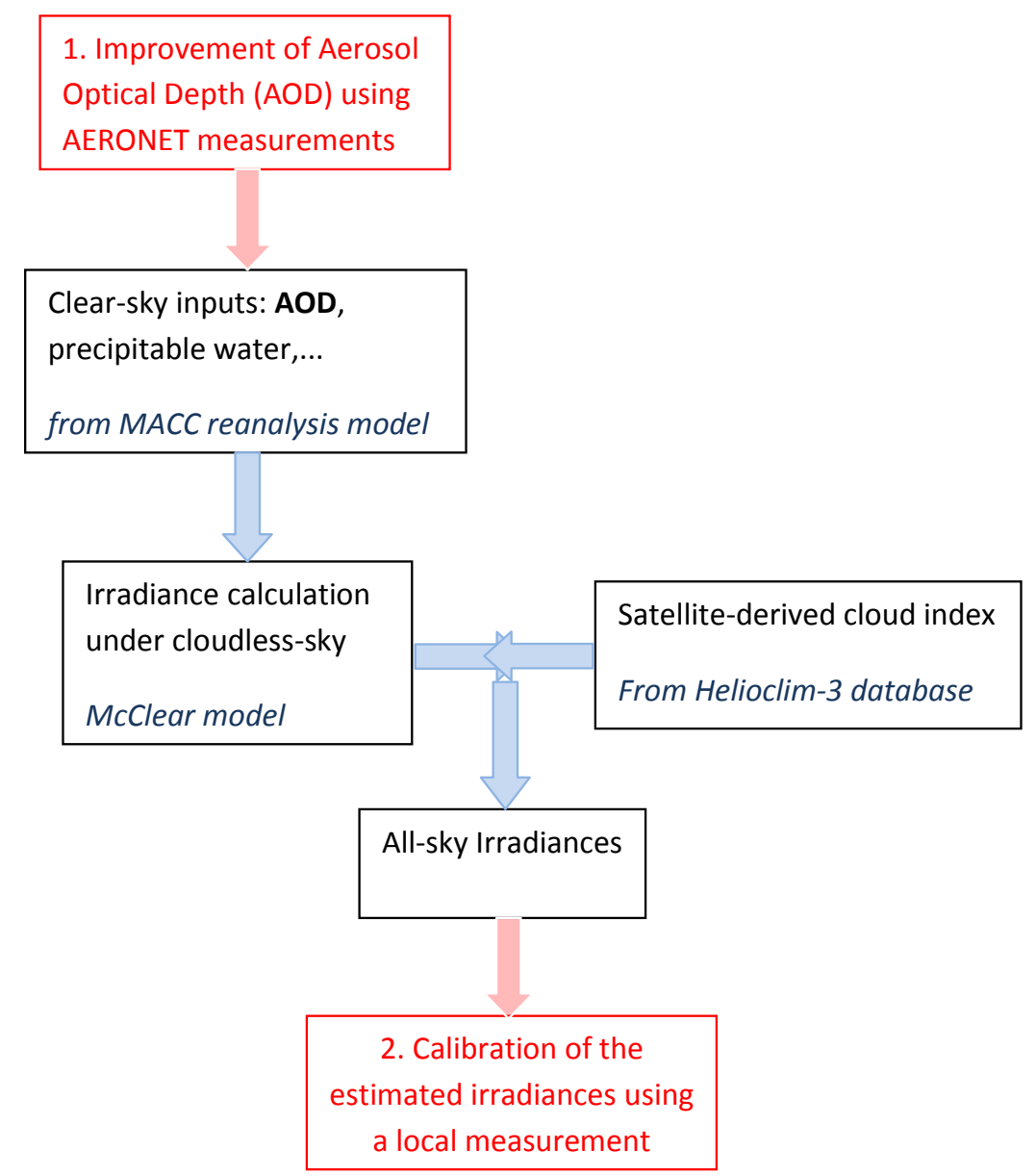

Fig. 1. Scheme of the Predisol model

The location map of the stations used in calibration and validation is shown in Figure 2.

\section{3. $A O D$ data and calibration}

The AOD is a particularly critical input for irradiance estimation in desert region given its less-frequent cloud coverage and its dusty atmosphere. MACC re-analysis model provides partial and total AODs in reduced Gaussian Grid resolution: $1.125^{\circ}$ in latitude, $1^{\circ}$ to $20^{\circ}$ in longitude from equator to pole (Benedetti et al., 2009). Every day at 0h, MACC predicts AODs at 0h, 3h, 6h, 9h, 12h, 15h, 18h and 21h (daily forecasting). Predicted quantities are total AOD at $550 \mathrm{~nm}$, total AOD at $1240 \mathrm{~nm}$, AOD of organic matter at $550 \mathrm{~nm}$, AOD of black carbon at $550 \mathrm{~nm}$, AOD of sea salt at $550 \mathrm{~nm}$, AOD of dust at $550 \mathrm{~nm}$ and AOD of sulphate at $550 \mathrm{~nm}$. The total AOD is the sum of all these individual AODs. The relative contribution of each aerosol species is used to determine the aerosol type, which is another input to McClear .

The NASA-operated AERONET program performs ground-based CIMEL CE-318 Sun photometer measurements, and converts them into estimates of aerosol optical properties. It provides a valuable validation data for satellite retrievals of aerosol optical properties. Datasets are available at 
http://aeronet.gsfc.nasa.gov and contain AOD measurements at 16 different wavelengths as well as solar zenith angles, total water vapor column measurements and several inversion coefficients. Measurements at some AERONET stations correspond to a time-limited campaign performed over a short period of time. In 2004 the United Arab Emirates Aerosol Experiment took place contributing to a remarkable increase in AERONET data availability in the Middle East. Therefore, the bulk of measurements in the Middle East correspond to 2004. Only 5 of the 16 stations in the UAE have more than one year of measurements. The AOD at $550 \mathrm{~nm}\left(\operatorname{AOD}_{\lambda=550 \mathrm{~nm}}\right)$ is derived from AERONET AOD at $440 \mathrm{~nm}$ and AOD at $870 \mathrm{~nm}$. AERONET level 2 - "cloud screened and quality assured" data were used in this study.

The comparison between MACC and AERONET AODs shows large deviations, partly due to the coarse spatial resolution of MACC. The MACC AOD product overestimates the AOD by $26 \%$ in the UAE. The relative root mean square deviation (RMSD) on the estimated AOD reaches $47 \%$, but the correlation coefficient was around 0.8 showing that MACC reproduces the temporal variability of AOD in the region relatively well. No daily variation of deviation is observed, though significant monthly changes were observed in the deviation. The highest bias of 0.16 is reached in July, corresponding to the highest mean AOD where the lowest bias (0.04) was obtained in November. Overall, the accuracy of MACC decreases when the AOD increases. These deviations lead to significant error in the estimation of irradiances. Over all the AERONET stations, the deviation - by the means of root mean square error (RMSE) - between irradiances estimated (using the radiative transfer model libRadtran) with MACC aerosols and irradiances estimated with AERONET is $5 \%$ for GHI and $20 \%$ for DNI. The general overestimation of AOD leads to underestimation of GHI and DNI. The differences between measured and AERONET derived irradiances notably increases with the distance, due to the modification of aerosol loading. When the AERONET and pyranometric stations are $100 \mathrm{~km}$ away, the standard deviation reaches $7 \%$ for GHI and $18 \%$ for DNI. This gives important information about the spatial variability of AOD in the UAE desert, and shows the limitation of using aerosol properties that are measured (or estimated) on locations or grid cells that are more than 100 km away. (Oumbe et al. 2012).

United Arab Emirates

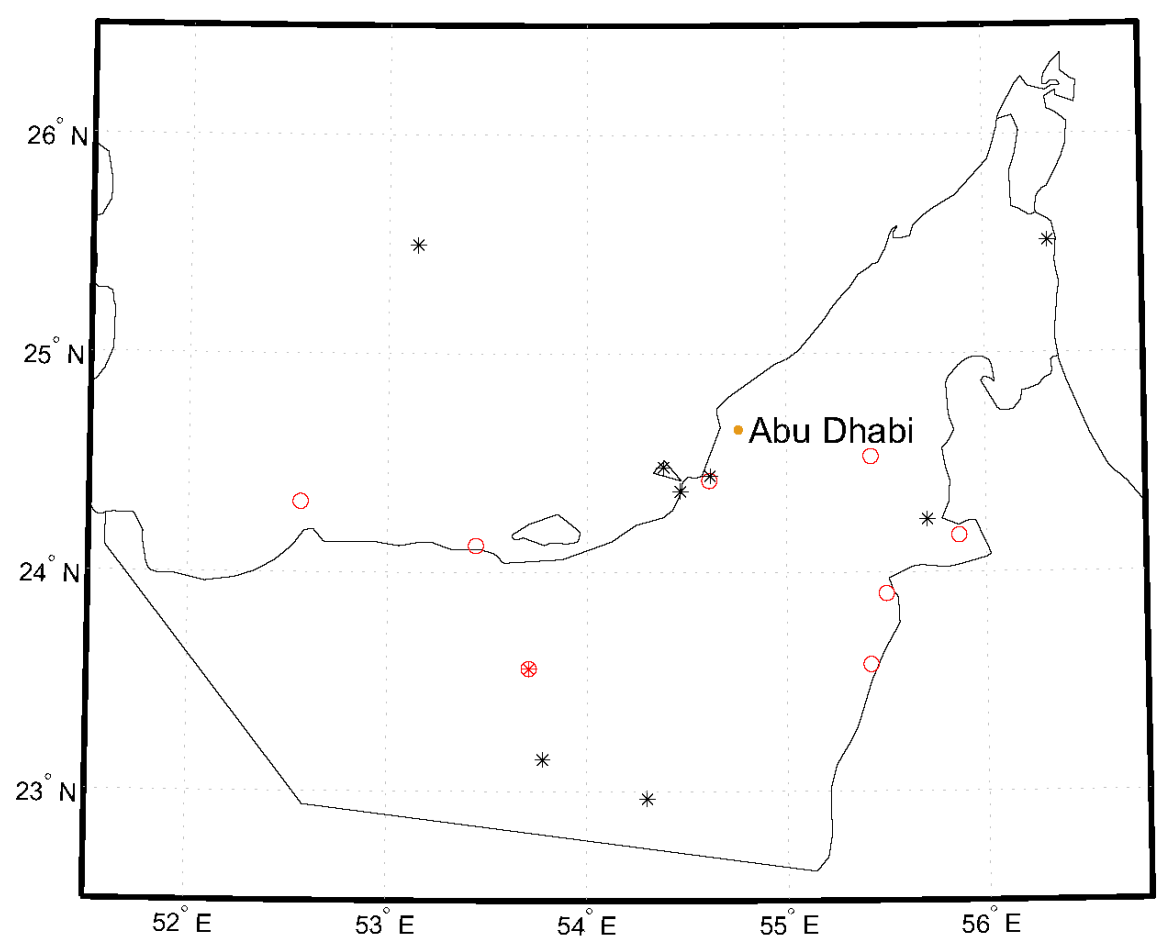

Fig. 2. Location of the Irradiance measuring stations (in red) and aerosol measuring stations (AERONET) (in black) in the UAE. The stars are stations used to calibrate the model (all AERONET and AD1) and the circles are stations used for model validation. 
Since the spatial resolution of MACC aerosol database is greater than $100 \mathrm{~km}\left(1.125^{\circ}\right)$, a local correction is necessary to properly reflect this actual spatial variability of the AOD. A correction function for MACC AOD was derived for each AERONET station. Then a global correction of MACC is AOD in the UAE was generated. This correction has improved the accuracy of AOD estimation at each AERONET station. The table 1 shows the performance of this correction: significant decrease of bias, noticeable decrease of RMSD, and no change in correlation coefficient.

\begin{tabular}{|c|c|c|}
\hline & Original AOD & Corrected AOD \\
\hline Bias & $26 \%(0.10)$ & $-2 \%(-0.01)$ \\
\hline RMSE & $47 \%(0.17)$ & $36 \%(0.13)$ \\
\hline Correlation coefficient & 0.797 & 0.797 \\
\hline
\end{tabular}

Table 1. Comparison between the original and the corrected MACC AOD and AERONET AOD. RMSE stands for root mean square error.

The Predisol clear-sky model was made of McClear operated with the MACC corrected AOD.

\subsection{Irradiance measurement and calibration}

The AD1 measuring station was specifically designed and commissioned for the Predisol project. It has been installed at Madinat Zayed near the Shams CSP plant. AD1 has provided high quality irradiance measurements with high temporal resolution. The station comprises the following instruments:

- a SOLYS 2 suntracker (Kipp \& Zonen) supporting the radiative sensors and allowing for sun tracking and DHI (Diffuse Horizontal Irradiance) sensor shading,

- a CHP1 first class pyrheliometer (Kipp \& Zonen) for measurement of the DNI component of irradiance. This sensor is equipped with a temperature probe in order to allow for temperature shift according to the sensor calibration curve,

- two secondary reference CMP11 Pyranometers (Kipp \& Zonen), one being unshaded for GHI measurement, the other being shaded by a shadow ball for DHI measurement,

- a meteorological mast equipped with wind measurement (Vaisala WMT520), temperature and HR measurements (Vaisala HMP155), atmospheric barometer (Vaisala BARO-1),

- a data acquisition module (Vaisala QML201) with storage capacity and modem for data transmission, and a 24V autonomous power supply (2x90 W peak PV panels $+2 \mathrm{x} 12 \mathrm{~V} / 130 \mathrm{Ah}$ batteries).

Datasets are reported in a 1-min average (DNI, GHI, DHI) or a 10-min average (Temperature, Relative humidity, Atmospheric Pressure, Wind speed, Wind direction). Within the measurement period we noticed some meteorological events that could affect the quality of solar data:

- Morning condensation during fall/winter, characterized by droplets condensing on sensors.

- $\quad$ Sand storms during spring/summer, characterized by sudden drop of GHI and DNI, the latter falling to zero.

- Large temperature excursions in summer. During these periods, the outside temperature exceeds $47^{\circ} \mathrm{C}$ during at least one hour a day.

The quality of the data was monitored based on the three component test (Roesch et al., 2011):

$$
\begin{aligned}
& \mathrm{GHI} /(\mathrm{DNI} * \cos (\mathrm{SZA})+\mathrm{DHI})=1.0 \pm 8 \% \text { for } \mathrm{GLOB} 1>50 \mathrm{Wm}^{-2}, \mathrm{SZA}<75 \\
& \mathrm{GHI} /(\mathrm{BNI} * \cos (\mathrm{SZA})+\mathrm{DHI})=1.0 \pm 15 \% \text { for } \mathrm{GLOB} 1>50 \mathrm{~W}^{-2}, 75<\mathrm{SZA}<93 \\
& \text { where SZA is the Sun Zenith Angle. }
\end{aligned}
$$

Routine maintenances (mainly cleaning and verification of alignment of the instruments) of the station were 
found critical to maintain the quality of the measurements. Figure 3 illustrates the correlation between the number of maintenance operations in a month and the percentage of data passing the three component test over the period from April 2012 to December 2013. August 2012 clearly appears as a "bad month" with only 6 maintenance operations and a poor fraction of good data (65\%). The poor result of October 2013 is due to the lack of DHI signal. Basically, in a desert region, at least one maintenance operation per day is needed for the high-precision station. TEMP1 is DNI* $\cos (\mathrm{SZA})+\mathrm{DHI}$.

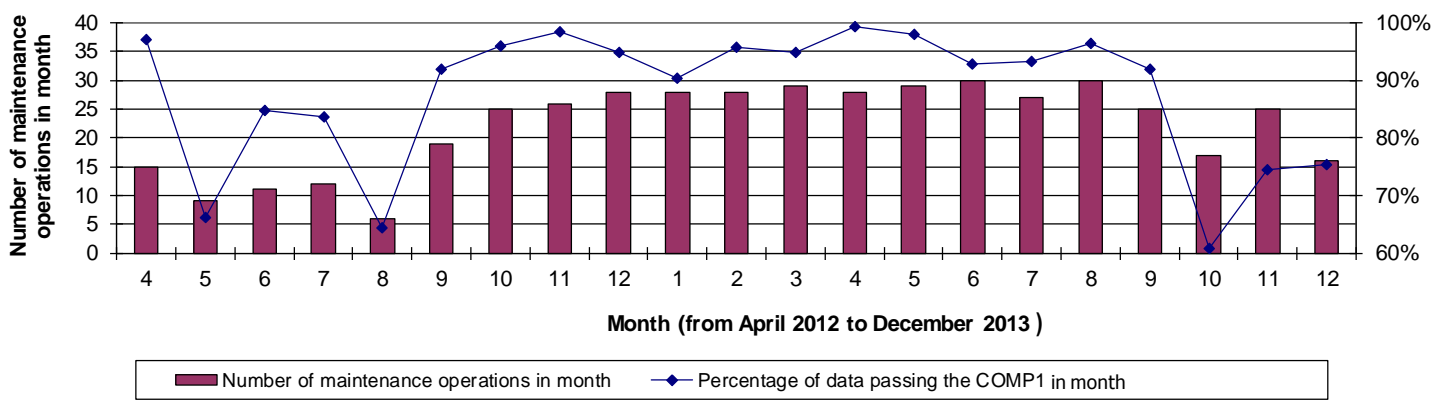

Fig. 3: Correlation between maintenance frequency and fraction of good solar data

The Predisol clear-sky model is proposed to replace the clear-sky model in the Middle East region of the HelioClim-3 database. This new database is calibrated with the quality-checked AD1 irradiance measurements. This calibration corrects systematic errors of the HelioClim-3 database in the region. E.g. we have noticed a clear under-estimation for the first hours in mornings, except in winter. After investigation, this almost systematic underestimation of GHI in the morning was found to be caused by the specular reflectance from the ground when the satellite observation direction is opposite to the sun direction, for high longitude. This under-estimation artifact due to high longitude implies a large global under-estimation of the non-calibrated GHI. The graphs presented in Figure 4 show the time series of the non-calibrated GHI and that of calibrated estimated GHI. With the calibration, the bias and RMSE drop respectively from $14 \%$ and $22 \%$ to $0 \%$ and $10 \%$. The calibrated database is the Predisol irradiance database.

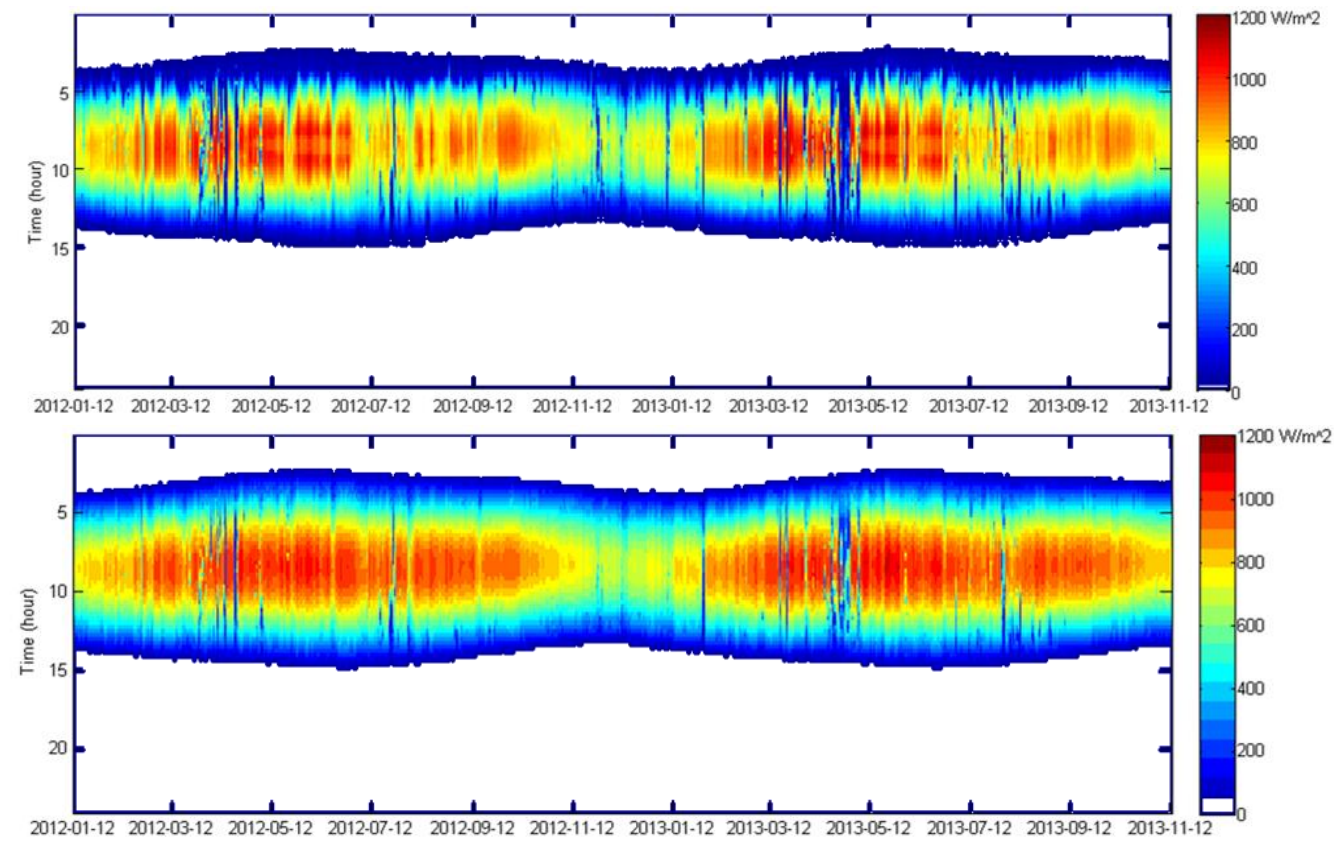

Figure 4: Timeseries of non-calibrated estimated GHI (at top) and of AD1 calibrated estimated GHI (at bottom) at AD1 station. Time is in UTC

A local transposition function has been then used to derive DNI from GHI. 


\section{Validation}

The estimated irradiances have been validated against high-quality measurements taken by 7 Rotating Shadowband Irradiometers (RSI) managed by Masdar Company and maintained by CSP Services. The RSI is a silicon photodiode, the LI-COR LI-200 Pyranometer, integrated with a rotating shadowband. When the shadowband is stationary below the horizon of the photodiode, the GHI is measured. The DHI is measured when the shadowband masks the entire solar disc from the pyranometer. The DNI is then derived from the GHI and DHI measurements. The shadowband rotates once per minute. The irradiances are averaged and delivered in a 10-minute time step. The locations of the RSI stations used for validation are shown by the red circles in Figure 2.

The 10-min measurements of RSIs, and the 15-min estimates of Predisol were averaged hourly irradiances. Each hour corresponds to the end of integration period ( $h$ for $] \mathrm{h}-1, \mathrm{~h}]$ ). The daily and monthly irradiation time-series were then computed. Deviations were computed by subtracting the measurements from the corresponding Predisol estimate. They were summarized by the bias, the standard deviation, the RMSE, and the Pearson correlation coefficient. Relative values are expressed with respect to the mean of the used measurements. See Table 2.

\begin{tabular}{|c|c|c|c|c|c|c|c|c|c|c|c|c|}
\hline & \multicolumn{4}{|c|}{ HOURLY MEANS (26229 hours) } & \multicolumn{4}{|c|}{ DAILY MEANS (2331 days) } & \multicolumn{4}{|c|}{ MONTHLY MEANS (68 months) } \\
\hline & Mean & Bias & RMSE & $C C$ & Mean & Bias & RMSE & $C C$ & Mean & Bias & RMSE & $C C$ \\
\hline DNI & $\begin{array}{l}458 \\
W / m^{2}\end{array}$ & $0 \%$ & $26 \%$ & 0.880 & $\begin{array}{l}5051 \\
W h / m^{2}\end{array}$ & $0 \%$ & $20 \%$ & 0.797 & $\begin{array}{l}154.1 \\
\mathrm{kWh} / \mathrm{m}^{2}\end{array}$ & $-1 \%$ & $10 \%$ & 0.805 \\
\hline GHI & $\begin{array}{l}552 \\
W / m^{2}\end{array}$ & $2 \%$ & $8 \%$ & 0.988 & $\begin{array}{l}6107 \\
\mathrm{Wh} / \mathrm{m}^{2}\end{array}$ & $2 \%$ & $6 \%$ & 0.966 & $\begin{array}{l}188.7 \\
\mathrm{kWh} / \mathrm{m}^{2}\end{array}$ & $2 \%$ & $4 \%$ & 0.990 \\
\hline
\end{tabular}

Table 2. Validation of global and direct irradiances. Measurements from all stations are combined. "Mean" is the mean of the measurements. CC stands for correlation coefficient. Bias and RMSE are expressed relative to "Mean".

Validation of the hourly means of irradiance show high coefficients of determination: 0.88 on DNI and 0.99 on GHI. The relative biases are close to zero: $0 \%$ on DNI and $2 \%$ on GHI and the relative root mean square error (RMSE) are low: $8 \%$ on GHI and $26 \%$ on DNI. Lower deviations are obtained on daily and monthly means of irradiance. There are still rooms for improvements on the DNI. These performances are better than those currently reported in the literature for the UAE (Eissa et al., 2012; Alobaidi et al., 2014; Gherboudj and Ghedira 2015).

The uncertainties of E-ANN (Eissa et al., 2013) for hourly irradiances in all-sky situations are similar for RMSE on DNI and higher for the bias on DNI and bias and RMSE on GHI. The relative bias and RMSE of E-ANN are respectively $6 \%$ and $26 \%$ for DNI and $3 \%$ and $12 \%$ for GHI. But the E-ANN validation is presented only on two stations. The ensemble artificial neural network (E-ANN) model, is a statistical model utilizing the Meteosat Second Generation images for irradiance prediction specifically over the region of the UAE. It requires a training beforehand. The E-ANN model was trained using reference data from three ground measurement stations for the full year of 2010 and validated over two independent stations for the full year of 2009 .

The cloud-free situations represent 60 to $80 \%$ in the region. The performance of McClear and E-ANN models for cloud-free situations, taken from Eissa et al (2015), are compared to those of the new method named Predisol (see Table 3). The enhancement of MACC AOD significantly reduces the bias on DNI estimation in cloud-free situations, leading Predisol to have less bias on DNI than McClear. The rest of performances of McClear and Predisol are close. McClear and Predisol perform better and E-ANN. 
Oumbe et al. / SWC 2015/ ISES Conference Proceedings (2015)

\begin{tabular}{|c|c|c|c|c|}
\hline & Model & Bias & RMSE & CC \\
\hline \multirow{2}{*}{$\begin{array}{c}\text { DNI } \\
(\text { mean of } \\
\text { measurements: } \\
\left.670 \mathrm{~W} / \mathrm{m}^{2}\right)\end{array}$} & E-ANN & $-9 \%$ & $19 \%$ & 0.607 \\
\cline { 2 - 5 } & McClear & $-4 \%$ & $11 \%$ & 0.837 \\
\cline { 2 - 5 } & Predisol & $\mathbf{- 0 . 6 \%}$ & $\mathbf{1 0 \%}$ & $\mathbf{0 . 8 9 4}$ \\
\hline $\begin{array}{c}\text { GHI } \\
(\text { mean of } \\
\text { measurements: } \\
\left.600 \mathrm{~W} / \mathrm{m}^{2}\right)\end{array}$ & E-ANN & $-6 \%$ & $11 \%$ & 0.947 \\
\cline { 2 - 5 } & McClear & $+2 \%$ & $5 \%$ & 0.982 \\
\cline { 2 - 5 } & Predisol & $\mathbf{+ 3 \%}$ & $\mathbf{5 \%}$ & $\mathbf{0 . 9 9 5}$ \\
\hline
\end{tabular}

Table 3. Validations of cloud-free hourly DNI and GHI by ANN, McClear and Predisol

\section{Conclusion}

The calibration method exhibit very satisfactory results on GHI and DNI estimations over the UAE, even though it was based only on one year of irradiance measurement at one site. The obtained accuracy was better than those reported in the literature for the UAE. The generated irradiance database -resolutions: $3 \mathrm{~km}$ and 15 minutes, period: 2004 to 2013- is therefore a reliable inputs data for feasibility studies and performance simulation of Solar Power Plant in the region. There is room for improvement of the DNI retrieval accuracy. It is expected that a higher resolution of AOD as inputs and /or a direct estimation of DNI, instead of transposition from GHI, would improve the model accuracy.

\section{References}

Alobaidi, M., Marpu, P., Ouarda,T., and Ghedira, H., 2014. Mapping of the Solar Irradiance in the UAE Using Advanced Artificial Neural Network Ensemble, Selected Topics in applied Earth Observations and Remote Sensing, Vol.7, Issue 8, pp.3668-3680.

Benedetti, A., Morcrette, J.-J., Boucher, O., Dethof, A., Engelen, R. J., Fisher, M., Flentje, H., Huneeus, N., Jones, L., Kaiser, J. W., Kinne, S., Mangold, A., Razinger, M., Simmons, A. J., and Suttie, M., 2009. Aerosol analysis and forecast in the European Centre for Medium-Range Weather Forecasts Integrated Forecast System: 2. Data assimilation. J. Geophys. Res. 114, D13205.

Beyer, H. G, Costanzo, C. and Heinemann, D., 1996. Modifications of the Heliosat procedure for irradiance estimates from satellite images. Sol. Energy, 56, 207-212.

Blanc, P., Gschwind, B., Lefèvre, M., and Wald L., 2011. The HelioClim Project: surface solar irradiance data for climate applications. Remote Sensing 3, 343-361.

Eissa,Y., Chiesa, M., and Ghedira, H., 2012. Assessment and recalibration of the Heliosat-2 method in global horizontal irradiance modeling over the desert environment of the UAE, Solar Energy, vol. 86, pp 1816-1825.

Eissa, Y., Marpu, P., Gherboudj, I., Ghedira, H., Ouarda, T., and Chiesa, M., 2013. Artificial neural network based model for retrieval of the direct normal, diffuse horizontal and global horizontal irradiances using SEVIRI images. Solar Energy, vol. 89, pp 1-16.

Eissa, Y., Munawwar, S., Oumbe, A., Blanc, P., Ghedira, H., Wald, L., Bru, H., and Goffe, D., 2015. Validating the downwelling solar irradiances estimated by the McClear model under cloud-free skies in the United Arab Emirates. Solar Energy 114, 17-31.

Gherboudj, I., and Ghedira, H., 2015. Assessment of solar energy potential over the United Arab Emirates using remote sensing and weather forecast data, Renewable and Sustainable Energy Reviews, In Press, doi:10.1016/j.rser.2015.03.099.

Lefèvre, M., Oumbe, A., Blanc, P., Espinar, B., Gschwind, B., Qu, Z,. Wald, L., Schroedter-Homscheidt, M., HoyerKlick, C., Arola, A., Benedetti, A., Kaiser, J. W., and Morcrette, J.-J., 2013. McClear: a new model estimating downwelling solar radiation at ground level in clearsky conditions. Atmos. Measur. Tech. 6, 2403-2418.

Oumbe, A., Qu, Z., Blanc, P., Lefèvre, M., Wald, L., and Cros, S., 2014. Decoupling the effects of clear atmosphere and clouds to simplify calculations of the broadband solar irradiance at ground level. Geoscientific Model Development, 7, 1661-1669. 
Oumbe et al. / SWC 2015/ ISES Conference Proceedings (2015)

Oumbe, A., Bru, H., Ghedira, H., Chiesa, M., Blanc, P., and Wald, L., 2012. Using AERONET to complement irradiance networks on the validation of satellite-based estimations, AGU Fall Meeting. http://adsabs.harvard.edu/abs/2012AGUFM.A1110172O

Rigollier, C., Lefèvre, M., and Wald, L., 2004. The method Heliosat-2 for deriving shortwave solar radiation data from satellite images. Solar Energy, 77(2), 159-169

Roesch, A., Wild, M., Ohmura, A., Dutton, E. G., Long, C. N., and Zhang, T., 2011, Assessment of BSRN radiation records for the computation of monthly means. in: Atmos. Meas. Tech., 4, 339-354.

Qu, Z., Gschwind, B., Lefèvre M., and Wald, L., 2014. Improving HelioClim-3 estimates of surface solar irradiance using the McClear clear-sky model and recent advances in atmosphere composition. Atmos. Meas. Tech., 7, 3927-3933. 